\title{
Artigo/Article
}

\section{Morbidade da doença de Chagas em pacientes autóctones da microrregião do Rio Negro, Estado do Amazonas}

\author{
Morbidity of Chagas disease among autochthonous patients from the Rio Negro microregion, \\ State of Amazonas
}

\author{
Lucia Maria Brum-Soares ${ }^{1}$, Sérgio Salles Xavier ${ }^{2}$, Andréa Silvestre de Sousa ${ }^{2}$, José Borges-Pereira ${ }^{1}$, João Marcos Bemfica \\ Barbosa Ferreira ${ }^{3}$, Inez Ribeiro Costa ${ }^{4}$, Angela Cristina Verissimo Junqueira ${ }^{1}$ e José Rodrigues Coura ${ }^{1}$
}

\begin{abstract}
RESUMO
Introdução. Foi realizado um estudo soroepidemiológico e clínico em 152 indivíduos residentes no município de Barcelos, Estado do Amazonas. Avaliou-se a soroprevalência da infecção chagásica e a morbidade da doença de Chagas. Métodos. Os testes sorológicos foram a imunofluorescência indireta, ELISA convencional e recombinante e o Tesa-blot. Foram considerados soropositivos 38 pacientes, duvidosos 31 e soronegativos negativos 83 . Os 38 casos soropositivos foram pareados com 38 controles soronegativos da mesma idade, sexo e submetidos à avaliação epidemiológica, clínica, eletro e ecocardiográfica, sendo que, 29 pares fizeram exame radiológico do esôfago. Resultados. A soropositividade foi 19,9 vezes mais frequente nos trabalhadores do extrativismo em geral e 10,4 vezes mais frequente no extrativismo da piaçaba. Aplicou-se o teste de reconhecimento com o vetor local do gênero Rhodnius e $86,7 \%$ dos pacientes soropositivos o reconheceram, enquanto somente $34,2 \%$ dos soronegativos o fizeram. O ECG mostrou-se alterado em $36,8 \%$ nos soropositivos e em $21,5 \%$ nos soronegativos, enquanto o ecocardiograma mostrou alterações em 31,6\% nos soropositivos e 18,4\% nos soronegativos. Precordialgia e palpitações foram mais frequentes nos soropositivos. O estudo clínico do aparelho digestivo e radiológico do esôfago não mostrou alterações significativas. Conclusões. A doença de Chagas na região estudada pode ser considerada uma doença ocupacional.
\end{abstract}

Palavras-chaves: Doença de Chagas. Trypanosoma cruzi. Morbidade. Estado do Amazonas.

\section{ABSTRACT}

Introduction. A seroepidemiological and clinical study was conducted on 152 autochthonous individuals living in the district of Barcelos, State of Amazonas, to evaluate the seroprevalence of Chagas infection and morbidity of Chagas disease. Methods. The serological tests used were indirect immunofluorescence, conventional and recombinant ELISA and immunoblot (Tesa-blot). Thirty-eight patients were considered seropositive; 31 were considered serodoubtful; and 83 were considered seronegative. The 38 seropositive cases were paired with 38 seronegative controls of the same age and sex, and underwent epidemiological and clinical evaluations, electrocardiograms and echocardiograms. Twenty-nine pairs underwent radiological examinations of the esophagus. Results. Seropositivity was 19.9 times more frequent among workers gathering plant materials from the forests and 10.4 times more frequent among piassaba gatherers. Eighty six point seven percent of the seropositive individuals recognized the genus Rhodnius as the local vector, while only $34.2 \%$ of the seronegative individuals recognized this. The EKG was abnormal in $36.8 \%$ of the seropositive individuals and in $21.5 \%$ of the seronegative individuals, while the echocardiogram showed abnormalities in $31.6 \%$ of the seropositive and $18.4 \%$ of the seronegative individuals. Precordialgia and palpitation were more frequent among the seropositive individuals. Clinical evaluation on the digestive system and X-ray on the esophagus did not show significant abnormalities. Conclusions. Chagas disease in the study region can be considered to be an occupational disease.
\end{abstract}

Key-words: Chagas disease. Trypanosoma cruzi. Morbidity. State of Amazonas.

1. Laboratório de Doenças Parasitárias, Instituto Oswaldo Cruz/Fundação Oswaldo Cruz, Rio de Janeiro, RJ. 2. Instituto de Pesquisas Clínicas Evandro Chagas/Fundação Oswaldo Cruz, Rio de Janeiro, RJ. 3. Hospital Universitário Francisca Mendes/Universidade Federal do Amazonas, Manaus, AM. 4. Escola Nacional de Ciências Estatísticas/Instituto Brasileiro de Geografia e Estatística, Rio de Janeiro, RJ.

Endereço para correspondência: Dra. Lucia Maria Brum-Soares. Laboratório de Doenças Parasitárias/ IOC/FIOCRUZ. Av. Brasil 4365, 21040-360 Rio de Janeiro, RJ.

Tel: $55212562-1326$ ou 552122803740

e-mail: brum24@gmail.com

Recebido para publicação em 25/08/2009

Aceito em 05/03/2010

\section{INTRODUÇÃO}

O primeiro caso humano documentado de infecção chagásica na Região Amazônica foi relatado em 1941 por Floch \& Tasque, na Guiana Francesa ${ }^{1}$. Já na Amazônia brasileira somente em 1969 foram descritos os quatro primeiros casos da infecção chagásica humana, em Belém do Pará por Shaw cols². Entre 1975 e 1980, foi realizado o inquérito sorológico nacional de prevalência da infecção chagásica, evidenciando resultados que sugeriram a existência de bolsões de transmissão em alguns municípios do país, destacando-se os da Amazônia Legal onde a soroprevalência foi acima da média nacional de $4,2 \%$, em locais como: Japurá (6,9\%), Novo Airão (6,8\%), Barcelos (6,3\%), no Estado do Amazonas, e Colares (5,1\%) no Estado do Pará3,4. Em 1977 foram detectados os seis primeiros casos de infecção chagásica humana autóctone do Estado do Amazonas em piaçabeiros do Município de Barcelos ${ }^{5}$, surgindo novas publicações em $1978^{6}$. Por outro lado, já foram encontradas dez das 16 espécies de triatomíneos descritas na região, e mais de 100 espécies de mamíferos de pequeno e médio porte, naturalmente infectados com o Trypanosoma $\mathrm{cruz}^{7-9}$.

Os dados da Secretaria de Vigilância em Saúde sobre a notificação de casos agudos da doença de Chagas na Amazônia legal desde 1969 a 2008 revelam aumento considerável do número de casos detectados, com 761 casos notificados ao longo de 40 anos, como pode ser observado na Figura 1. Cabe destacar que entre 2002 e 2008 foram registrados $75 \%$ (568 casos) do total de casos notificados na região Amazônica ${ }^{10-12}$.

A forma como a infecção pelo Trypanosoma cruzi se manifesta clinicamente é variável. As variações nas apresentações clínicas regionais podem ser explicadas por diferenças na carga parasitária e pelas cepas de T. cruzi que possuem afinidades histotrópicas variáveis, atribuídas aos mecanismos de pressão biológica, exercidos por vetores e reservatórios, 


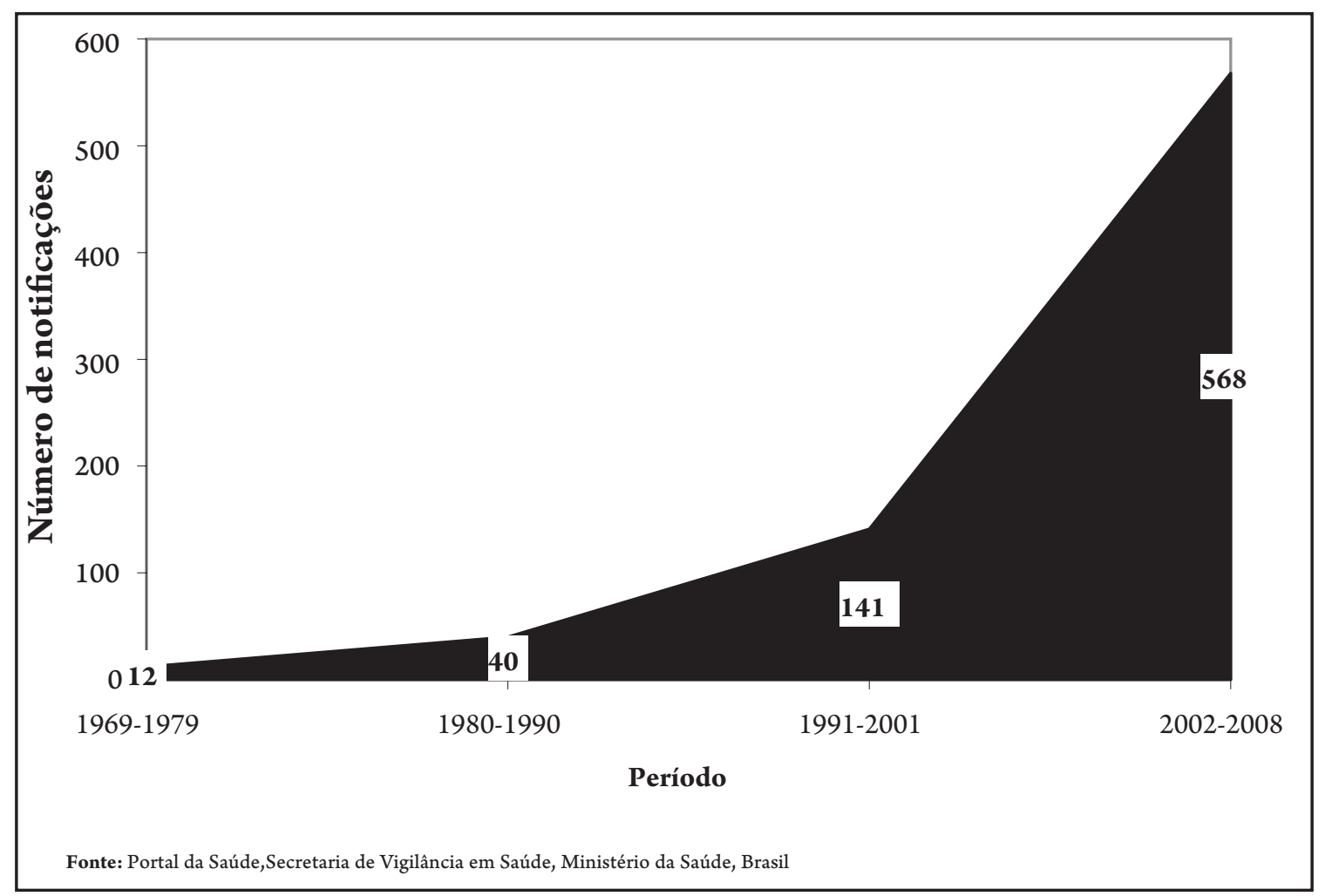

FIGURA 1 - Série histórica de 1969 a 2008 das notificações de casos agudos de doença de Chagas na Amazonia Legal.

podendo ser mais ou menos patogênicas para o homem. Por este motivo é mais comum o diagnóstico de formas digestivas na região central do Brasil, assim como é baixa a prevalência de cardiopatias ao norte da linha do equador em relação ao sul. Nesse sentido, é necessário um melhor estudo da doença de Chagas na Região Amazônica, onde tem se concentrado nos últimos anos a maioria das notificações.

A maioria dos casos agudos notificados de infecção chagásica na Amazônia Legal, até o momento, associa-se a surtos familiares através da transmissão por via oral do T. cruzi ${ }^{11-14}$. Entretanto, foram descritos bolsões de transmissão em áreas de grande concentração vetorial, como os piaçabais da palmeira Leopoldinia piassaba, localizados na Microrregião do Médio Rio Negro, onde a transmissão ocorre pelo contato direto com o vetor, Rhodnius brethesi, que ataca os extrativistas da fibra e seus familiares ${ }^{7,8,15-17}$. Alguns estudos clínicos com pacientes autóctones da Região Amazônica demonstram uma fase aguda exuberante com marcada morbidade ${ }^{11-14}$. No entanto, pouco se sabe sobre o curso crônico da doença de Chagas e o peso social da morbidade nesta região exceto por relatos de casos isolados de cardiopatia chagásica crônica ${ }^{18,19}$.

Com o objetivo de avaliar o perfil clínico durante a fase crônica da infecção chagásica em uma área da Microrregião do Médio Rio Negro, foi realizado um estudo seccional envolvendo 152 indivíduos autóctones a fim de investigar os aspectos soroepidemiológicos, clínicos, radiográficos, eletro e ecocardiográficos, na mencionada região.

\section{MÉTODOS}

O estudo foi realizado no Município de Barcelos, Estado do Amazonas, que segundo dados do Instituto Brasileiro de Geografia e Estatística possuí população de 24.567 habitantes e extensão territorial de $122.475 .728 \mathrm{~km}^{2}$, localizando-se na margem direita do Rio Negro a 490km de Manaus por via fluvial ${ }^{20}$.
Participaram deste estudo 152 indivíduos autóctones que foram convocados por diversos meios (radiofonia, rádio comunitária e cartas). Todos foram informados sobre os tipos de exames realizados na pesquisa e, como voluntários, assinaram o consentimento de sua participação. Após os resultados sorológicos, os 152 indivíduos foram subdivididos em três grupos, compostos por 38 indivíduos soropositivos, 83 soronegativos e 31 sorodivergentes. Os 38 indivíduos soropositivos foram pareados com 38 soronegativos, de acordo com o gênero e a idade.

\section{Aspectos clínico-epidemiológicos}

Todos os indivíduos foram submetidos a um questionário direcionado para a investigação dos aspectos relacionados à transmissão e manifestações clínicas da infecção chagásica, bem como submetidos durante a consulta à anamnese e exame físico direcionados fundamentalmente ao sistema cardiovascular e digestivo. Na investigação sobre a transmissão, aplicou-se um teste de reconhecimento vetorial para o qual se preparou uma fotografia (em tamanho natural) e placas de Petri com triatomíneos das espécies Rhodnius brethesi, Panstrongylus megistus e Triatoma infestans, fixados em formol. Solicitou-se aos entrevistados que relataram contato prévio com triatomíneos que apontassem na foto e no mostruário com qual ou quais das espécies haviam estado em contato.

\section{Considerações estatísticas}

Trata-se de um estudo observacional, seccional. A amostragem foi por conveniência, tendo em vista que todos que compareceram ao ambulatório foram examinados e incluídos na pesquisa. Os dados coletados foram armazenados e analisados através dos programas EpiData 3.1 e SPSS 16, respectivamente. O teste de Fisher foi utilizado para verificar se as proporções de alterações eletrocardiográficas dos indivíduos soropositivos e dos soronegativos para a infecção chagásica estavam associadas ou não as idades dos indivíduos. $\mathrm{O}$ teste para proporções em amostras independentes foi aplicado 
para determinar se houve diferença, estatisticamente significativa, entre os grupos de indivíduos soropositivos e soronegativos para a infecção chagásica quanto às alterações clínicas, radiológicas, eletro e ecocardiográficas. Considerou-se o nível de significância de 5\% para rejeitar a hipótese nula. Utilizou-se a razão de chances (odds ratio) para avaliar a probabilidade de o indivíduo ter sorologia positiva ou negativa para infecção chagásica em relação à atividade laboral que desempenhou, considerando-se atividades de extrativismo (piaçaba, sorva, balata, seringa, castanha e açaí) e atividades não ligadas ao extrativismo (pesca, agricultura, guia turístico, etc.) a fim de comparar qual destas atividades aumentaria a probabilidade de um indivíduo apresentar sorologia positiva para infecção chagásica.

\section{Estudo sorológico}

Foram coletados de cada indivíduo $10 \mathrm{ml}$ de sangue venoso, para centrifugação e obtenção do soro, mantido a $20^{\circ} \mathrm{C}$, até o processamento. Os testes empregados foram: IFI-CHAGAS (Bio-Manguinhos, Cut off 1:40), EIEChagas (Bio-Manguinhos, Cut off = 0,205), ELISA-CHAGATEST recombinante v.3.0 (Wiener, Cut off $=0,306$ ) e o TESA-blot (positivo na presença de banda de $160 \mathrm{kDa}$ ). Consideramos como positivos para a infecção chagásica os soros que além de apresentar uma IFI reagente com titulações maiores ou iguais a 1:40 foram também positivos em pelo menos outros dois testes com diferentes preparações antigênicas. Foram considerados negativos os indivíduos nos quais todos os resultados foram não reagentes nos quatro testes empregados. Indivíduos com resultados sorológicos divergentes (positivo em apenas um dos testes) ou que se mantiveram na zona cinza mesmo após várias repetições (referentes aos resultados obtidos com os kits de ELISA) foram excluídos deste estudo pela impossibilidade de confirmar ou descartar a infecção chagásica nos mesmos.

\section{Estudos parasitológicos e moleculares}

Entre os 38 indivíduos com sorologia confirmadamente positiva, para infecção chagásica crônica, 24 foram submetidos aos exames de xenodiagnóstico, hemocultura e PCR. Em cada xenodiagnóstico foram aplicadas 40 ninfas de $3^{\circ}$ e/ou $4^{\circ}$ estádios, sendo 20 de Panstrongylus megistus e 20 de Rhodnius brethesi (vetor local), subdivididas em quatro caixas apropriadas para este exame. Todos os 24 indivíduos submetidos ao xenodiagnóstico direto receberam um anti-histamínico oral (maleato de dexclofeniramina $2 \mathrm{mg}$ ) 30 minutos antes da aplicação dos mesmos sobre os antebraços e após aplicou-se loção de calamina sobre o local de repasto dos triatomíneos para minimizar possíveis reações alérgicas. Após 45 dias da aplicação, realizou-se o exame, ao microscópio óptico, das dejeções e/ou do tubo digestivo de cada ninfa. Para a hemocultura, de cada paciente foi obtido um volume de $30 \mathrm{ml}$ de sangue venoso em três tubos vacutainers de $10 \mathrm{ml}$, em seguida à centrifugação por 10 minutos a $2.500 \mathrm{rpm} \mathrm{a} 4^{\circ} \mathrm{C}$, o sedimento de cada tubo foi adicionado em outro tubo contendo $10 \mathrm{ml}$ de meio LIT (Liver Infusion Tryptose). Os três tubos de cada paciente foram armazenados a $28^{\circ} \mathrm{C}$ em estufa BOD e a leitura do material foi feita ao microscópio óptico aos 30, 60, 90 e 120 dias depois do cultivo inicial. Para a reação em cadeia de polimerase, utilizada para detectar DNA de T. cruzi no sangue periférico, coletou-se um volume de $10 \mathrm{ml}$ de sangue venoso de cada paciente com imediatamente transferência para um outro tubo contendo $10 \mathrm{ml}$ de solução guanidina $\mathrm{HCl}$ (gianidine-hydrochloride) e EDTA (ácido etilenodiaminotetracético), o qual foi mantido a temperatura ambiente até o processamento no Laboratório. Utilizouse como alvo de amplificação a região variável dos minicírculos de kDNA, empregando os primers 121 e 122. O resultado foi considerado positivo quando o produto amplificado apresentava banda de 330 pares de bases.

\section{Exames radiográficos}

Foram examinados, por meio de radiografia ântero-posterior 29 indivíduos com sorologia positiva para infecção chagásica e 29 indivíduos com sorologia negativa para definir a cardiomegalia diante do índice cardiotorácico (ICT) maior que 0,5. A presença de megaesôfago foi avaliada com uma radiografia oblíqua anterior direita, obtida 60 segundos após a ingestão de $75 \mathrm{ml}$ do contraste (Bariogel ${ }^{\oplus}, \mathrm{BaSO} 4$ 100\%). A presença de megaesôfago seria considerada, caso todos os critérios estabelecidos na classificação de Rezende ${ }^{21}$ fossem rigorosamente cumpridos, fato que não ocorreu. Devido à impossibilidade técnica em realizar o estudo radiológico do cólon (o diagnóstico da forma indeterminada foi sugerido) os indivíduos foram avaliados de forma subjetiva através da anamnese sobre períodos de constipação e objetivamente por meio do exame físico na busca de fecalomas palpáveis.

\section{Eletrocardiograma}

Todos os indivíduos foram submetidos a um eletrocardiograma em repouso, com registro das doze derivações clássicas D1, D2, D3, aVR, aVL, aVF, V1, V2, V3, V4, V5 e V6, com padrão N (1mV=10 mm) ou N/2 ( $1 \mathrm{mV}=5 \mathrm{~mm})$, em casos de QRS de grande amplitude, com pelo menos três complexos por derivação e um D2 longo ${ }^{22,23}$. Os traçados foram interpretados de acordo com critérios da New York Heart Association ${ }^{24}$. A leitura do traçado eletrocardiográfico foi realizada por dois cardiologistas de forma cega, utilizando o código de Minnesota, adaptado para doença de Chagas. Consideraram-se as seguintes alterações como mais sugestivas de doença de Chagas: Bloqueio completo do ramo direito com ou sem hemibloqueio anterior esquerdo (HBAE), extrassístoles ventriculares, bradicardia sinusal com frequência cardíaca $<50 \mathrm{bpm}$, bloqueio atrioventricular de $2^{\circ}$ grau, alterações primárias da repolarização ventricular, presença de áreas eletricamente inativas, disfunção do nó sinusal, taquicardia ventricular não sustentada, fibrilação atrial, bloqueio atrioventricular total e bloqueio de ramo esquerdo. Por outro lado, foram consideradas não sugestivas, quando isoladas no traçado: bradicardia sinusal, baixa voltagem, bloqueio intermitente do ramo direito, hemibloqueio anterior esquerdo, bloqueio atrioventricular de $1^{\circ}$ grau e alterações inespecíficas de ST-T.

\section{Ecocardiograma}

Em todos os 76 indivíduos pareados realizou-se ecocardiograma (ECO) uni e bidimensional, utilizando-se os cortes convencionais paraesternais, apicais, subcostais e supraesternais, além de variações dos mesmos, visando uma melhor identificação de alterações segmentares localizadas, especialmente nas zonas póstero-inferior e apical como os aneurismas de ponta. A função sistólica do ventrículo esquerdo foi avaliada de forma objetiva através do cálculo da fração de ejeção pelo método de Teichholz e Kreulen ${ }^{25}$, além de avaliação semiquantitativa, definindo a disfunção como leve, moderada ou grave.

\section{Classificação da forma cardíaca}

Aplicou-se a nova classificação adotada pelos Consensos Brasileiro e Latino Americano de Insuficiência Cardíaca e recomendada pelo Consenso Brasileiro em Doença de Chagas que leva em consideração a função sistólica ventricular esquerda, obtida através da ecocardiografia, ademais de aspectos eletrocardiográficos 
e clínicos, permitindo a identificação de subgrupos $\left(\mathrm{A}, \mathrm{B}_{1}, \mathrm{~B}_{2}, \mathrm{C}\right.$ e D) distintos do ponto de vista prognóstico e terapêutico. A classificação segue os seguintes critérios: estágio A: eletrocardiograma alterado e ecocardiograma normal; estágio B1: eletro e ecocardiograma alterados, com fração de ejeção do ventrículo esquerdo superior a 45\%; estágio B2: eletro e ecocardiograma alterados com fração de ejeção do ventrículo esquerdo inferior a $45 \%$ sem sinais de insuficiência cardíaca; estágio C: todos os critérios do estágio B2 associados a um quadro de insuficiência cardíaca compensada; e estágio D: alterações eletro e ecocardiográficas com fração de ejeção inferior a $45 \%$ associada ao quadro de insuficiência cardíaca refratária ao tratamento ${ }^{26,27}$.

\section{Ética}

O presente estudo seguiu as diretrizes e normas que regulamentam as pesquisas em seres humanos, de acordo com a Resolução 196/96 do Conselho Nacional de Saúde. O projeto foi aprovado pelo Conselho de Ética em Pesquisa com seres humanos do Instituto de Pesquisas Clínicas Evandro Chagas da Fundação Oswaldo Cruz, protocolo $\mathrm{n}^{\circ}$ 0019.0.009.000.07.

\section{RESULTADOS}

\section{Aspectos clínico-epidemiológicos}

Na Tabela 1, estão distribuídos os 152 indivíduos soropositivos, soronegativos e sorodivergentes de acordo com a faixa etária. A distribuição da variável idade foi praticamente homogênea entre os 38 indivíduos soropositivos e os 83 soronegativos, variando de 7 a 81 anos. A média de idade entre os soropositivos foi de 45 anos, a mediana foi de 42 anos e o desvio padrão foi de 17,1 anos. Entre os soronegativos, a média foi de 46 anos, a mediana foi de 48 anos e o desvio padrão 16,1 anos.

TABELA 1 - Distribuição dos indivíduos soronegativos, soropositivos e sorodivergentes para anticorpos IgG anti-T. cruzi por faixa etária, BarcelosAmazonas, 2008.

\begin{tabular}{|c|c|c|c|c|c|c|}
\hline \multirow[b]{2}{*}{ Faixa etária (anos) } & \multicolumn{2}{|c|}{ Soronegativos } & \multicolumn{2}{|c|}{ Soropositivos } & \multicolumn{2}{|c|}{ Sorodivergentes } \\
\hline & $\mathrm{n}^{\mathrm{o}}$ & $\%$ & $\mathrm{n}^{\mathrm{o}}$ & $\%$ & $\mathrm{n}^{\mathrm{o}}$ & $\%$ \\
\hline 7 a 16 & 2 & 2,4 & 2 & 5,3 & 2 & 6,4 \\
\hline 17 a 26 & 11 & 13,2 & 3 & 7,9 & 7 & 22,6 \\
\hline 27 a 36 & 12 & 14,5 & 9 & 23,7 & 3 & 9,7 \\
\hline 37 a 46 & 14 & 16,9 & 9 & 23,7 & 8 & 25,8 \\
\hline 47 a 56 & 22 & 26,5 & 4 & 10,5 & 5 & 16,1 \\
\hline 57 a 66 & 12 & 14,5 & 5 & 13,2 & 5 & 16,1 \\
\hline 67 a 81 & 10 & 12,0 & 6 & 15,8 & 1 & 3,2 \\
\hline Total & 83 & 100,0 & 38 & 100,0 & 31 & 100,0 \\
\hline
\end{tabular}

Antes de apresentar os resultados do teste de Fisher é importante considerar que no grupo de soropositivos para infecção chagásica, $52 \%$ dos indivíduos com alterações eletrocardiográficas estavam abaixo dos 46 anos de idade; e que no grupo de 83 indivíduos com sorologia negativa apenas $22 \%$ dos que apresentaram alterações eletrocardiográficas tinham menos que 46 anos de idade.

Aplicou-se o teste de Fisher no grupo de indivíduos soropositivos com eletrocardiograma alterado. $\mathrm{O}$ resultado mostrou que não existem evidências na amostra para afirmar que ter alterações no eletrocardiograma dependa da faixa etária em que se encontre o indivíduo, considerando que o valor observado $(0,74)$ é menor que o valor crítico $(3,84)$, com nível de significância de $5 \%$. O mesmo teste quando aplicado ao grupo de indivíduos soronegativos para infecção chagásica com alterações no eletrocardiograma, revelou que ter alterações no eletrocardiograma depende da faixa etária, considerando que o valor observado $(5,65)$ foi maior que o valor crítico $(3,84)$, ao nível de $5 \%$.

Através do cálculo da razão de chances (odds ratio) verificou-se que as atividades laborais associadas ao extrativismo aumentam em 19,9 vezes a chance de um indivíduo apresentar sorologia positiva para infecção chagásica quando comparada a outras atividades não relacionadas com o extrativismo. Ao comparar quais tipos de extrativismo aumentam a probabilidade de um indivíduo apresentar sorologia positiva para infecção chagásica, encontrou-se que a prática especificamente do extrativismo da piaçaba aumenta em 10,4 vezes a chance de um indivíduo apresentar sorologia positiva se comparado a outras atividades extrativistas, como a extração da balata, da castanha, da seringa, do açaí ou sorva.

Quanto aos hábitos tóxicos constatou-se que 32\% dos indivíduos soropositivos eram etilistas, 34\% eram tabagistas e 3\% utilizaram drogas ilícitas. Entre os indivíduos com sorologia negativa para infecção chagásica, verificou-se que 33\% eram etilistas, $24 \%$ eram tabagistas e $4 \%$ utilizaram drogas ilícitas, não havendo diferenças estatisticamente significativas entre os dois grupos, ao nível de 5\%.

Com a aplicação do teste de identificação de vetores, observouse que $94,7 \%$ dos indivíduos soropositivos identificaram o vetor e 5,3\% não o reconheceram. Entre os $95 \%$ que reconheceram o vetor, $86,8 \%$ apontaram o gênero Rhodnius, seguido do gênero Panstrongylus com 5,3\% e o Triatoma com 2,6\% de reconhecimento. Entre os soronegativos para infecção chagásica, 52,6\% reconheceram o vetor, sendo que $34,2 \%$ reconheceram o gênero Rhodnius, $10,5 \%$ o Panstrongylus e $7,9 \%$ o gênero Triatoma. No entanto, $48,4 \%$ dos soronegativos não reconheceram o vetor.

A análise estatística dos inversos de títulos dos testes de IFI no grupo de 38 soropositivos mostrou uma média de 164, a mediana de 80 e o desvio padrão de 192, enquanto na ELISA recombinante, o índice de reatividade (densidade óptica da amostra de soro/cut off) apresentou-se com média de 6,6; mediana de 7,7 e desvio padrão de 2,7. Entre os sorodivergentes observou-se que a maioria apresentava-se com o teste de IFI positivo e os ensaios imunoenzimáticos negativos.

Dos 38 pares soropositivos/soronegativos, 29 (76,3\%) eram do gênero masculino e nove $(23,7 \%)$ do gênero feminino, expressando a maior participação dos homens nesse grupo de estudo. Nos 38 indivíduos soropositivos para infecção chagásica as manifestações clínicas de natureza cardiovasculares estiveram presentes em $16(42,1 \%)$ e as digestivas em dez (26,3\%). Entre os 38 indivíduos soronegativos, nove (23,7\%) apresentaram manifestações cardiovasculares e 12 (15,8\%) manifestações digestivas; não houve diferença estatística significativa entre os grupos ao nível de 5\%. Na Tabela 2, estão discriminadas as principais manifestações clínicas consideradas neste estudo em ambos os grupos, assim como os números absolutos de indivíduos afetados, os percentuais e os seus respectivos p-valores.

\section{Exames parasitológicos}

Apenas um (4\%) caso o xenodiagnóstico foi positivo, sendo que o T. cruzi foi detectado em quatro ninfas de Panstrongylus megistus das 20 aplicadas, todas as 20 ninfas da espécie Rhodnius brethesi aplicadas foram negativas. Tratava-se de um paciente masculino de 32 anos de idade, hígido, conhecido de outros estudos e que já havia sido tratado com benzonidazol em duas ocasiões anteriores, relatava haver se afastado durante este período dos piaçabais. Todas as hemoculturas realizadas no grupo de 24 pacientes soropositivos 
TABELA 2 - Manifestações clínicas dos 38 pares de indivíduos soropositivos e soronegativos para infecção chagásica, Barcelos-Amazonas, 2008.

\begin{tabular}{|c|c|c|c|c|c|}
\hline \multirow[b]{2}{*}{ Manifestações Clínicas } & \multicolumn{2}{|c|}{ Soropositivos } & \multicolumn{2}{|c|}{ Soronegativos } & \multirow[b]{2}{*}{ p-Valor* } \\
\hline & $\mathrm{n}^{\mathrm{o}}$ & $\%$ & $\mathrm{n}^{\mathrm{o}}$ & $\%$ & \\
\hline \multicolumn{6}{|l|}{ Cardiovasculares } \\
\hline precordialgia & 11 & 28,9 & 6 & 15,8 & 0,084 \\
\hline palpitações & 12 & 31,6 & 8 & 21,1 & 0,149 \\
\hline dispnéia ao esforço & 4 & 10,5 & 3 & 7,9 & 0,344 \\
\hline arritmia à ausculta & 3 & 7,9 & 2 & 5,3 & 0,323 \\
\hline perda da consciência & 3 & 7,9 & 1 & 2,6 & 0,151 \\
\hline hipertensão arterial & 4 & 10,5 & 5 & 13,2 & 0,363 \\
\hline sopro sistólico & 2 & 5,3 & 1 & 2,6 & 0,277 \\
\hline \multicolumn{6}{|l|}{ Digestivas } \\
\hline pirose & 7 & 18,4 & 5 & 13,2 & 0,264 \\
\hline disfagia & 6 & 15,8 & 3 & 7,9 & 0,142 \\
\hline regurgitação passiva & 2 & 5,3 & 0 & 0,076 & \\
\hline obstipação de até 7 dias & 3 & 7,9 & 2 & 5,3 & 0,323 \\
\hline obstipação > 7 dias & 1 & 2,6 & 1 & 2,6 & 0,5 \\
\hline uso de laxativo & 2 & 5,3 & 1 & 2,6 & 0,277 \\
\hline fecaloma à palpação & 0 & 0 & & & \\
\hline
\end{tabular}

*Teste para proporções em amostras independentes.

apresentaram-se negativas aos exames até 120 dias de semeadura. A PCR foi positiva em cinco (20,8\%) indivíduos dos 24 soropositivos avaliados indicando uma baixa parasitemia.

\section{Exames radiológicos, eletro e ecocardiográficos}

Os resultados dos exames radiológicos, eletrocardiográficos e ecocardiográficos estão expressos na Tabela 3. Entre os 29 indivíduos
TABELA 3 - Resultados da área cardíaca, eletrocardiograma e ecocardiograma em 38 pares de indivíduos soropositivos (sorop) e soronegativos (soron) para infecção chagásica, Barcelos-Amazonas, 2008.

\begin{tabular}{|c|c|c|c|c|c|c|c|c|c|c|c|c|}
\hline \multirow[b]{3}{*}{ Resultados } & \multicolumn{4}{|c|}{ Área cardíaca (ICT) } & \multicolumn{4}{|c|}{ Eletrocardiograma } & \multicolumn{4}{|c|}{ Ecocardiograma } \\
\hline & \multicolumn{2}{|c|}{ sorop } & \multicolumn{2}{|c|}{ soron } & \multicolumn{2}{|c|}{ sorop } & \multicolumn{2}{|c|}{ soron } & \multicolumn{2}{|c|}{ sorop } & \multicolumn{2}{|c|}{ soron } \\
\hline & $\mathrm{n}^{\mathrm{o}}$ & $\%$ & $\mathrm{n}^{\mathrm{o}}$ & $\%$ & $\mathrm{n}^{\mathrm{o}}$ & $\%$ & $\mathrm{n}^{\mathrm{o}}$ & $\%$ & $\mathrm{n}^{\mathrm{o}}$ & $\%$ & $\mathrm{n}^{\mathrm{o}}$ & $\%$ \\
\hline Normal & 25 & 86,2 & 26 & 89,5 & 24 & 63,2 & 30 & 78,9 & 26 & 68,4 & 31 & 81,6 \\
\hline Alterado & 4 & 13,8 & 3 & 10,5 & 14 & 36,8 & 8 & 21,0 & 12 & 31,6 & 7 & 18,4 \\
\hline Total & 29 & 100,0 & & 100,0 & 38 & 100,0 & & 100,0 & 38 & 100,0 & 38 & 100,0 \\
\hline
\end{tabular}

com sorologia positiva, quatro $(13,8 \%)$ apresentaram ICT $>0,5$, sendo considerados alterados; nos outros 25 indivíduos (86,2\%) o exame foi considerado normal. Enquanto nos 29 indivíduos com sorologia negativa, avaliados radiologicamente três $(10,5 \%)$ apresentaram ICT maior que 0,5 ; o restante foi considerado normal. Não houve diferença estatística significativa ao nível de 5\%. A radiografia de esôfago contrastado não evidenciou a presença de megaesôfago nos 29 pares de indivíduos avaliados, ressaltando-se que seis indivíduos soropositivos e três soronegativos que referiram disfagia durante a anamnese foram examinados para a detecção de megaesôfago, mas não se detectou alterações compatíveis que cumprissem os critérios estabelecidos por Rezende cols ${ }^{21}$.

Entre os 38 indivíduos com sorologia positiva, 14 (36,8\%) apresentaram alterações eletrocardiográficas (Tabela 4) e 24 (63,2\%) foram considerados normais. No grupo de 38 soronegativos, oito $(21,5 \%)$ indivíduos apresentaram alterações eletrocardiográficas, nos outros $30(78,5 \%)$ indivíduos, os eletrocardiogramas foram considerados normais. Não houve diferença estatística significante de alterações eletrocardiográficas entre os grupos de soropositivos

TABELA 4 - Frequências das alterações eletrocardiográficas e ecocardiográficas em 38 indivíduos soropositivos e soronegativos para infecção chagásica, BarcelosAmazonas, 2008.

\begin{tabular}{|c|c|c|c|c|}
\hline \multirow[b]{2}{*}{ Alterações } & \multicolumn{2}{|c|}{ Soropositivos } & \multicolumn{2}{|c|}{ Soronegativos } \\
\hline & $\mathrm{n}^{\mathrm{o}}$ & $\%$ & $\mathrm{n}^{\mathrm{o}}$ & $\%$ \\
\hline \multicolumn{5}{|l|}{ Eletrocardiográficas } \\
\hline alteração primária da repolarização ventricular & 3 & 7,9 & 1 & 2,6 \\
\hline alteração inespecífica da repolarização em parede inferior & 0 & - & 2 & 5,3 \\
\hline bradicardia sinusal $(\mathrm{fc}<50 \mathrm{bpm})$ & 1 & 2,6 & 0 & - \\
\hline bloqueio do ramo direito III + hemibloqueio anterior esquerdo + extra-sístoles ventriculares multifocais & 2 & 5,3 & 0 & - \\
\hline bloqueio do ramo direito $\mathrm{I}+$ hemibloqueio anterior esquerdo & 1 & 2,6 & 0 & - \\
\hline bloqueio do ramo direito I & 1 & 2,6 & 1 & 2,6 \\
\hline bloqueio do ramo direito III & 0 & - & 1 & 2,6 \\
\hline bloqueio do ramo esquerdo III & 1 & 2,6 & 1 & 2,6 \\
\hline hemibloqueio anterior esquerdo & 3 & 7,9 & 0 & - \\
\hline desvio do eixo elétrico para a direita + sobrecarga de câmara esquerda & 0 & - & 2 & 5,3 \\
\hline \multicolumn{5}{|l|}{ Ecocardiográficas } \\
\hline total de ECO alterados & 12 & 31,6 & 7 & 18,4 \\
\hline déficit de relaxamento & 2 & 5,3 & 3 & 7,9 \\
\hline cardiopatia dilatada padrão difuso + disfunção sistólica grave de $\mathrm{VE}(\mathrm{FE}<23 \%)+$ disfunção diastólica padrão restritivo + estenose aórtica grave & 2 & 5,3 & 1 & 2,6 \\
\hline válvula aórtica bicúspide + regurgitação leve/moderada & 1 & 2,6 & 1 & 2,6 \\
\hline escleroe valvar aórtica com leve regurgitação & 1 & 2,6 & 1 & 2,6 \\
\hline prótese aórtica normofuncionante com aneurisma do seio de valsalva & 0 & - & 1 & 2,6 \\
\hline cardiopatia dilatada padrão segmentar + disfunção sistólica $(\mathrm{FE}<45 \%)+$ aneurisma apical & 2 & 5,3 & 0 & - \\
\hline déficit de relaxamento + esclerose valvar aórtica & 2 & 5,3 & 0 & - \\
\hline insuficiência mitral leve & 1 & 2,6 & 0 & - \\
\hline movimento anômalo no septo interventricular & 1 & 2,6 & 0 & - \\
\hline
\end{tabular}


e soronegativos, ao nível de 5\%. Em 12 (31,6\%) indivíduos, dos 38 com sorologia positiva, foram encontradas alterações ecocardiográficas, sendo que dois indivíduos apresentaram aneurisma em dedo de luva no ápice do ventrículo esquerdo. Entre os 38 indivíduos com sorologia negativa para a infecção chagásica, sete $(18,4 \%)$ apresentaram alterações ecocardiográficas; nos demais indivíduos, os ecocardiogramas foram considerados normais. Ao nível de significância de 5\%, não houve diferença estatística entre as proporções de alterações ecocardiográficas entre os grupos de soropositivos e soronegativos. A Tabela 4 mostra os tipos de alterações eletrocardiográficas e ecocardiográficas encontradas no grupo de indivíduos soropositivos e nos indivíduos soronegativos para a infecção chagásica.

Ao classificar as alterações eletrocardiografias e ecocardiográficas em sugestivas e inespecíficas para cardiopatia chagásica crônica, pode-se observar, de forma relativa que entre os 14 indivíduos com sorologia positiva que apresentaram eletrocardiogramas alterados, as alterações foram sugestivas de doença de Chagas em cinco (36\%) indivíduos e inespecíficas em nove (64\%) indivíduos.

Entre os 38 indivíduos com sorologia positiva, observamos que $24(63,2 \%)$ destes estavam na forma indeterminada sugerida. A forma cardíaca foi detectada em 14 (36,8\%). Não foi identificado nenhum indivíduo com a forma digestiva. Considerando que $21,5 \%$ dos indivíduos com sorologia negativa também mostraram alterações eletrocardiográficas, podemos estimar o componente exclusivamente chagásico em $15,8 \%$, ou seja, o coeficiente de morbidade cardiológica ou risco atribuível à doença de Chagas.

Utilizando-se a nova classificação da forma cardíaca adotada pelos Consensos Brasileiro e Latino Americano de Insuficiência Cardíaca e recomendada pelo Consenso Brasileiro em Doença de Chagas ${ }^{26,27}$, observamos que seis $(15,8 \%)$ indivíduos estavam no estágio A, quatro (10,5\%) indivíduos estavam no estágio B1, dois $(5,3 \%)$ indivíduos no estágio $\mathrm{B} 2$, um $(2,6 \%)$ no estágio $\mathrm{C}$ e um $(2,6 \%)$ no estágio $\mathrm{D}$.

\section{DISCUSSÃO}

O cenário eco-epidemiológico da doença de Chagas, na Amazônia brasileira apresenta alguns desafios para o futuro: um deles é gerar estratégias para conter a rápida transformação do estado de enzootia em antropozoonose expressa pela emergência de centenas de casos agudos ${ }^{11-14}$ e crônicos ${ }^{7,8,15,18,19}$ nas últimas seis décadas; outro desafio é determinar as causas da crescente ocorrência de surtos de infecção pelo T. cruzi, os quais têm sido atribuídos a transmissão por via oral, principalmente pela ingestão da polpa do açaí, hábito incorporado há séculos na cultura alimentar regional. Para esses dois eventos ainda não há explicações testadas; entretanto, pode-se observar que os mesmos são contemporâneos à intensidade do processo de ocupação da floresta amazônica, que gera mudanças nos nichos ecológicos, determinando a emergência de agravos como a doença de Chagas. Observamos que a instalação da endemia chagásica na região amazônica apresenta-se com os mesmos determinantes da endemização ocorrida nas demais regiões do Brasil, nas quais dominaram os modelos de colonização e produção agropecuária, aliados a ocupação desordenada do espaço.

O aumento considerável do número de casos agudos notificados na região amazônica ${ }^{11-14}$ pode ser atribuído à melhoria do seu diagnóstico, sem deixar de considerar outros fatores, em parte produzidos pela ação antrópica (desmatamentos, aumento da densidade demográfica, a caça indiscriminada de animais silvestres, entre outros), além das características biológicas dos vetores da região, ainda pouco estudadas.

A transmissão do T. cruzi na região por nós estudada é predominantemente vetorial e está fundamentalmente associada à atividade laboral do extrativismo da piaçava, ou seja, a transmissão vetorial não é dependente de domiciliação, pois a espécie responsável identificada pela quase totalidade dos indivíduos soropositivos, o Rhodnius brethesi, ataca o homem no ambiente de trabalho ou de descanso, como foi evidenciado por Coura cols ${ }^{7}$. Esses achados são relevantes por indicarem a necessidade de formulação de estratégias de controle e vigilância epidemiológica específicas para a doença de Chagas na Microrregião do Médio Rio Negro.

A maior participação de indivíduos masculinos no grupo de estudo, também identificada por Coura cols $\mathrm{s}^{8,15} \mathrm{em}$ estudos anteriores, confirma a forte associação entre a aquisição da infecção chagásica e atividades laborais, em especial as associadas ao extrativismo da piaçaba, desempenhada predominantemente por indivíduos masculinos, cujo risco de contrair infecção pelo T. cruzi foi 10 vezes maior do que aqueles que trabalhavam no extrativismo de outros produtos. Esse risco indica que doença de Chagas nessa região pode ser considerada como agravo do trabalho ou da atividade profissional, diferente da maioria dos resultados observados em áreas endêmicas do Nordeste, Sudeste e Sul do Brasil, nas quais a soroprevalência é maior no grupo de mulheres, atribuída hipoteticamente ao fato de que as mulheres permanecem mais tempo no intradomicílio, o que aumenta o risco de infecção chagásica transmitida principalmente por espécies como T. infestans, $P$. megistus e T. brasiliensis com elevados graus de domiciliação.

A análise dos resultados sobre o comportamento da sorologia, avaliada principalmente pelo teste de IFI, indicou que os indivíduos chagásicos da região estudada apresentam baixo nível sérico de IgG antiT. cruzi, expressando, provavelmente, baixa carga parasitária com baixo potencial antigênico do parasito circulante ou baixa capacidade de resposta imune humoral dos indivíduos, ou por conta de ambos os fatores. Esse achado coloca os indivíduos chagásicos dessa região no grupo de pacientes com baixo nível de IgG anti-T. cruzi em comparação principalmente com pacientes de áreas endêmicas de Minas Gerais ${ }^{28}$ e Piauíi ${ }^{29}$.

A análise dos resultados sobre a parasitemia, com percentuais de xenodiagnósticos e reação em cadeia da polimerase respectivamente de $4 \%$ e $20,8 \%$, revela que esses valores são significativamente menores do que os percentuais encontrados em áreas endêmicas do Sudeste ${ }^{30}$ e Nordeste ${ }^{31,32}$. Essa diferença de níveis de circulação sanguínea de parasitos nos seres humanos na fase crônica precisa ser testada em animais de laboratório, na tentativa de avaliar o papel da diversidade das cepas na variação regional (T. cruzi I, T. cruzi III e T. cruzi IV, predominantes na Região Norte do Brasil e T. cruzi II, predominante nas Regiões Nordeste e Sudeste do Brasil, conforme revisão recente publicada $)^{33}$.

A análise global dos resultados sobre a morbidade nos conduziu a considerar pequena a probabilidade de haver megaesôfago na população chagásica da região estudada, porém existe cardiopatia crônica com baixa prevalência atribuível à etiologia exclusivamente chagásica. A cardiopatia crônica em pacientes soropositivos para anticorpos anti-T. cruzi da Região do Rio Negro tem sido descrita em publicações de casos feitas por Albajar cols ${ }^{18}$, Xavier cols ${ }^{19}$ e mais 
recentemente por Ferreira $\operatorname{cols}^{34}$. Confirmando a baixa morbidade da infecção chagásica expressa em poucos casos graves, entre os 38 pacientes soropositivos da presente casuística, foram encontrados somente dois pacientes com quadro clínico considerado grave, ou seja, nos estágios C e D da classificação do Consenso ${ }^{26}$.

Em relação à distribuição da variável idade, foi praticamente similar entre o grupo de soropositivos e de soronegativos. O resultado do teste de Fisher sugere que no grupo de soropositivos as alterações eletrocardiografias não dependem da faixa etária, já que 52\% dos indivíduos com alterações cardíacas estão abaixo dos 46 anos de idade, devendo haver outro fator causal, possivelmente atribuível à ação do próprio T. cruzi sobre o miocárdio.

Consideramos a classificação das formas clínicas da infecção chagásica como indeterminada, cardíaca e digestiva, porém devemos ressaltar que a forma indeterminada foi sugerida, pois não houve estudo radiográfico do cólon (devido à limitação de recursos técnicos na área), mas também pela raridade de alterações digestivas em zonas onde circula o T. cruzi I.

Não houve diferenças significativas quanto aos hábitos tóxicos entre os grupos soropositivos e soronegativos, minimizando a possibilidade de que o predomínio de alterações clínicas fosse atribuível à influência dos mesmos em determinado grupo. Embora $36,8 \%$ de forma cardíaca seja uma proporção elevada para uma área considerada de baixa morbidade, destacamos, neste estudo, que a baixa morbidade não implica em ausência ou baixa incidência de alterações clínicas, e que as mesmas devem ser acompanhadas de forma evolutiva para estimar o peso social atribuível à morbidade da doença de Chagas naquela região.

Quanto aos tipos dos parasitos circulantes na área de estudo, isolados em estudo anteriores, foram classificados como T. cruzi I e T. cruzi Z3, os quais têm apresentado baixa patogenicidade para camundongos, atribuindo-se também a essa característica a baixa morbidade da infecção por dificuldade de adaptação do parasito à infecção humana na área ${ }^{8,35}$. Entretanto, o mesmo não ocorre na fase aguda da doença, na qual vários casos apresentam manifestações clínicas exuberantes ${ }^{11-14} \mathrm{o}$ que contrasta com o reduzido número de casos crônicos sintomáticos na área entre os sorologicamente confirmados. Contudo, devido à casuística reduzida, novos estudos padronizados devem ser realizados com o objetivo de se estimar o impacto social da morbidade chagásica na microrregião do Médio Rio Negro.

\section{AGRADECIMENTOS}

Júlio César Miguel, Maria Celeste Dias Spata, Laura Cristina Santos, Patrícia Lago Zauza, Dra. Eufrosina Setsu Umezawa, Maria José da Silva de Souza, agentes de saúde da Prefeitura Municipal de Barcelos, Prof. Joffre Marcondes Rezende, Dr. Pedro Viñas Albajar, Prof. Alexandre César Maretto Federici, monitores da Escola Nacional de Ciências Estatísticas do Instituto Brasileiro de Geografia e Estatística e ao Conselho Nacional de Desenvolvimento Científico e Tecnológico.

\section{CONFLITO DE INTERESSE}

Os autores declaram não haver nenhum tipo de conflito de interesse no desenvolvimento do estudo.

\section{SUPORTE FINANCEIRO}

Conselho Nacional de Desenvolvimento Científico e Tecnológico. (CNPq).

\section{REFERÊNCIAS}

1. Floch H, Tasque P. Um cãs de maladie de Chagas em Guyane Française: Bull Soc Path Exot $1941 ; 36: 37$.

2. Shaw J, Lainson R, Fraiha H. Considerações sobre a epidemiologia dos primeiros casos autóctones de doença de Chagas registrados em Belém, Pará, Brasil. Rev Saude Publica 1969; 3:153-157.

3. Camargo ME, Silva GR, Castilho EA, Silveira AC. Inquérito sorológico da prevalência da infecção chagásica no Brasil, 1975- 1980. Rev Instit Med Trop São Paulo 1984; 26:192-204.

4. Silveira AC \& Passos ADC. Altos índices de prevalência sorológica da infecção chagásica em área da Amazônia. Rev Soc Bras Med Trop 1986; 19: 45.

5. Ferraroni JJ, Melo JAN, Camargo ME. Moléstia de Chagas na Amazônia. Ocorrência de seis casos suspeitos, autóctones, sorologicamente positivos. Acta Amazônica (Manaus) 1977; 7: 438-440.

6. Almeida FB, Nunes de Mello JA. Sobre a ocorrência de moléstia de Chagas no Estado do Amazonas, Brasil. Acta Amazônica 1978; 8: 595-599.

7. Coura JR, Barret TV, Arboleda MN. Ataque de populações humanas por triatomíneos silvestres no Amazonas: uma nova forma de transmissão da infecção de Chagas? Rev Soc Bras Med Trop 1994; 27: 251-253.

8. Coura JR, Junqueira ACV, Fernandes O, Valente SAS, Miles MA. Emerging Chagas disease in Amazonian Brazil. Trends in Parasitol 2002; 18: 171-176.

9. Deane LM. Tripanosomídeos de mamíferos da região Amazônica.III. Hemoscopia e xenodiagnóstico de animais silvestres dos arredores de Belém, Pará. Rev Inst Med Trop São Paulo 1964; 6: 225-232.

10. Governo da República Federativa do Brasil, Ministério da Saúde. Disponível em: http://portal.saude.gov.br/portal/saude/profissional/area.cfm?id_area $=1530$ Acessado em: 12/04/09 às 16:43 pm.

11. Pinto AYN, Valente AS, Valente VC, Ferreira AG, Coura JR. Fase aguda da doença de Chagas na Amazônia brasileira: estudo de 233 casos do Pará, Amapá e Maranhão observados entre 1988 e 2005. Rev Soc Bras Med Trop 2008; 41: 602-614.

12. Pinto AYN. Estudo de Casos agudos de doença de Chagas tratados e sua evolução para formas crônicas no Pará e Amapá, Amazônia. Tese de Doutorado, Instituto Oswaldo Cruz, Medicina Tropical, Rio de Janeiro; 2006. p. 121.

13. Valente SA, Costa Valente V, Neves Pinto AY, Jesus Barbosa César M, Santos MP, Miranda CO, et al. Analysis of an acute Chagas disease outbreak in the Brazilian Amazon: human cases, triatomines, reservoir mammals and parasites. Trans Royal Soc Trop Med Hyg 2009; 103: 291-297.

14. Valente SAS, Valente VC, Pinto AYN, Fraiha Neto H. Microepidemia familiar e transmissão oral da doença de Chagas na Amazônia brasileira. Memórias do Instituto Oswaldo Cruz 2000; 95: 69-72.

15. Coura JR, Arboleda MN, Willcox HPF. Chagas' disease in the Brazilian Amazon. II. A serological survey. Rev Inst Med Trop São Paulo 1995; 37: 103-107.

16. Matta A. Sobre o gênero Rhodnius do Amazonas. Amazonas médico (Manaus) 1922; 5: 161-162.

17. Matta A. Um novo reduvídeo do Amazonas. Rhodnius brethesi n. sp. Amazonas médico (Manaus) 1919; 2: 93-94.

18. Albajar PV, Laredo SV, Terrazas MB, Coura JR. Miocardiopatia dilatada em pacientes com infecção chagásica crônica. Relato de dois casos fatais autóctones do Rio Negro, Estado do Amazonas. Rev Soc Bras Med Trop 2003; 36: 401407.

19. Xavier SS, Sousa AS, Coura JR, Vinas PA. Chronic chagasic cardiopathy in the Rio Negro, Amazon State. Report of three new autochthonous cases confirmed by serology, clinical examination, chest X-rays, electro and echocardiography. Rev Soc Bras Med Trop 2006; 39: 211-216. 
20. Governo da República Federativa do Brasil, Ministério do Planejamento, Orçamento e Gestão, Instituto Brasileiro de Geografia e Estatística. Disponível em: http://www.ibge.gov.br/cidades. Acessado em 07/06/09 às 13:21 pm.

21. Rezende JM, Lauar KM, Oliveira AR. Aspectos clínicos e radiológicos da aperistalsis do esôfago. Rev Bras Gastroenterol 1960; 12: 247-262.

22. Maguire JH, Hoff R, Sherlock I, Guimarães AC, Sleigh AC, Ramos NB, Mott KE. Cardiac morbidity and mortality due to Chagas' disease: prospective electrocardiographic study of Brazilian community. Circulation 1987; 75: 11401145 .

23. Rose G, Blackburn H, Gillium RF, Prineas RJ. Cardiovascular survey methods. World Health Organization, Monograph Series; 1982. p. 56.

24. New York Heart Association. Nomenclature and criteria for diagnosis of diseases of the heart and great vessels. Little Brown and Company, Boston; 1973.

25. Teicholz LE, Kreulen T. Problems in echocardiographic volume determinations: Echocardiographic correlations in the presence or absence of asynergy. Am J Cardiol 1976; 37: 7-11.

26. Consenso Brasileiro em Doença de Chagas. Rev Soc Bras Med Trop 2005; 38: 29 .

27. Xavier SS, Sousa AS, Moreno AH. Aplicação da nova Classificação da Insuficiência Cardíaca (ACC/AHA) na Cardiopatia Chagásica Crônica: Análise critica das curvas de sobrevida. Rev Soc Card Estado do Rio de Janeiro, Rio de Janeiro 2005; 18: 227-232.

28. Zauza PL, Borges-Pereira J. Níveis séricos de IgG anti-Trypanosoma cruzi na evolução da cardiopatia chagásica crônica, no período de 10 anos. Rev Soc Bras Med Trop 2001; 34: 399-405.

29. Borges-Pereira J, Castro JAF, Campos JHF, Nogueira JS, Zauza PL, Marques P, et al. Estudo da infecção e morbidade da doença de Chagas no município de João Costa: Parque Nacional Serra da Capivara, Piauí, Brasil. Rev Soc Bras Med Trop 2002; 35: 315-322.

30. Wincker P, Britto C, Pereira JB, Cardoso MA, Oelemann W, Morel CM. Use of a polymerase simplified chain reaction procedure to detect Trypanosoma cruzi in blood samples from chronic chagasic patients in a rural endemic area. Am J Trop Med Hyg 1994; 51: 771-777.

31. Britto C, Cardoso MA, Ravel C, Santoro A, Pereira JB, Coura JR, et al. Trypanosoma cruzi: Parasite detection and strain discrimination in chronic chagasic patients from northeasten Brazil using PCR amplification of kinetoplast DNA and nonreactive hybridization. Exp Parasitol 1995; 81: 462-471.

32. Junqueira ACV, Chiari E, Wincker P. Comparison of the polymerase chain reaction with two classical parasitological methods for the diagnosis of Chagas disease in an endemic region of north-eastern Brazil. Trans Royal Soc Trop Med Hyg 1996; 90: 129-132.

33. Zingales B, Andrade SG, Briones MRS, Campbell DA, Chiari E, Fernandes O, et al. A new consensus for Trypanosoma cruzi intraspecific nomenclature: second revision meeting recommends Tcl to TcVI. Mem Inst Oswaldo Cruz 2009; 104: 1051-1054.

34. Ferreira JMBB, Guerra JAO, Barbosa MGV. Ventricular aneurysm in a chronic Chagas disease patient from the Brazilian Amazon region. Rev Soc Bras Med Trop 2009; 42: 474-475.

35. Andrade Z. Patologia da doença de Chagas. In: Brener Z, Andrade Z, Barral Neto M, editores. Trypanosoma cruzie doença de Chagas, Ed. Guanabara 2a edição; 2000. p. 201-230. 